\title{
Research Paper: Evaluating the Efficacy of Positive Psychotherapy on Life Expectancy in Students With Hemophilia: A Randomized Controlled Trial
}

\author{
Mahbobe Ghavidel Heydari $^{1}$ (D), Mahmoud Shirazi2 ${ }^{\text {* }}$ (D), Gholam Reza Sanagouyemoharer ${ }^{1}$ (iD)
}

1. Department of Psychology, Faculty of Psychology and Educational Sciences, Zahedan Branch, Islamic Azad University, Zahedan, Iran. 2. Department of Psychology, Faculty of Education and Psychology, University of Sistan and Baluchestan, Zahedan, Iran

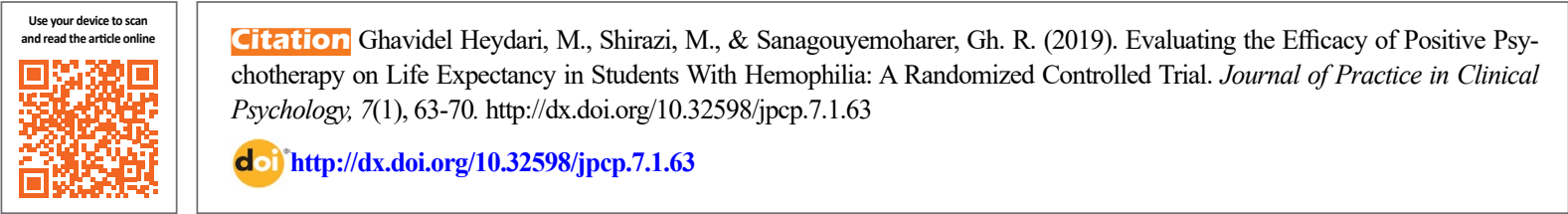

(i) (5)

Article info:

Received: 23 Mar 2018

Accepted: 10 Oct 2018

Available Online: 01 Jan 2019

Keywords:

Hemophilia, Positive

psychotherapy, Life

expectancy, Students

\section{ABSTRACT}

Objective: Hemophilia is a genetic bleeding disorder results from a deficient in synthesis of a protein needed for blood clotting. The number of people with hemophilia in the United States is about 20,000. Iran having the ninth largest Hemophilia population in the world. Hemophilia lead to many psychological and physiological complications. Therefore, this study aimed to evaluate the effectiveness of positive psychotherapy on the Life expectancy as one of psychological aspects in hemophilia students.

Methods: The present study is a quasi-experimental interventional study along with experimental and control groups. The subjects were evaluated in the pre-test, post-test and two-month follow-up. Study population including all senior elementary and junior high school students with hemophilia who had medical records in Zahedan Hemophilia Society. After screening, 60 students were selected and randomly assigned into two 30-member groups of experimental and control. The research tool was Snyder Children's Hope Scale questionnaire (1991). Positive psychotherapy workshop was held in 8 sessions (Two 120 minutes sessions weekly) and followup test was done two months after the end of the last training session. The obtained information was analyzed through repeated measurement variance.

Results: The results show significant effectiveness of positive psychotherapy on increasing Life expectancy in patients with hemophilia and indicated the durability of this therapy in the follow-up stage. In this research we highlighted the need for training and using positive psychotherapy as a new, safe and effective psychological therapy for student suffering Hemophilia.

Conclusion: We emphasize for the implication of this study result and method by clinicians and policy makers to manage psychological problems of students suffering from Hemophilia.

\section{* Corresponding Author:}

Mahmoud Shirazi, $P h D$

Address: Department of Psychology, Faculty of Education and Psychology, University of Sistan and Baluchestan, Zahedan, Iran.

Tel: +98 (915) 3404219

E-mail:mahmoud.shirazi96@gmail.com 


\section{Highlights}

- Children with hemophilia have significantly lower life expectancy compared with healthy children.

- Positive psychotherapy is considered as a cognitive psychological strategy.

- Positive psychotherapy workshop significantly increased life expectancy score in children with hemophilia.

\section{Plain Language Summary}

Hemophilia is a chronic disease. Many children in our country suffer from this disease. Children affected by this disease commonly present lower life expectancy score in comparison with healthy children. In this study, we investigated the effectiveness of positive psychotherapy, which is a safe, cost-effective and easy to perform method to help patients to manage their psychological problems related to hemophilia. The results indicate that this treatment is an effective method to improve the life expectancy of the study patients.

\section{Introduction}

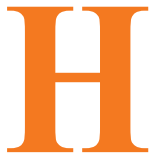

emophilia is an inherited genetic disorder. In this disorder, severe and spontaneous bleeding may occur because of an insufficient blood-clotting factor in the body. Depending on the shortage of coagulation factor in the blood, the severity of the disease will be different (DeKoven et al., 2014; Iannazzo et al., 2017). Commonly, the bleeding happen into the joint spaces (hemarthrosis), especially in the knees, ankles, and elbows. It also causes intracranial and postoperative bleeding (Hosseini et al., 2014). Frequent and severe bleeding, movement limitations and other complications will eventually result in emotional and life-threatening problems (Chen et al., 2015). Because of their special medical care (Jafari, Mohtashami, Alaee Karahroudi, Mansouri, \& Rassouli, 2016).

The normal activities of the patients and even their family members and people around them will be significantly and negatively affected (Sidonio, Holot, \& Cooper, 2017). On the other hand, drugs side-effects, immobilization, frequent absences from school and school dropout (Cassis, Querol, Forsyth, Iorio, \& Board, 2012), economic costs imposed on individuals and society (Poon, Doctor, \& Nichol, 2014; Rezende et al., 2017; Sondik, Madans, \& Gentleman, 2010), infection with hepatitis B, C viruses and some special treatments that result in inappropriate physical appearances in many patients lead to disturbances in feeling good and wellbeing, and affect the quality of the patients' relationships with others (Klein \& Nimorwicz, 1982).
Considering that the most part of the Iran health care subsidy is spent on the patients with hemophilia and onefifth of the total cost of importing medicine are allocated to hemophilia patients, it is one of the most expensive diseases in Iran. Given that the majority of hemophiliacs living in the country's distant provinces and challenged with the medicines shortage in addition to above-mentioned problems, the Life expectancy of students with hemophilia is unfortunately short (Dorgalaleh, Dadashizadeh, \& Bamedi, 2016; Karimi \& Haghpanah, 2015).

In recent years, psychologists have investigated the structure of hope and believe that hope is one of the foundational principles of mental power and balance of human minds (Griggs, 2017; Shorey, Snyder, Yang, Lewin, \& Psychology, 2003). Psychologists believe that hope can improve several aspects of life such as mental health, education, work, and personal meaning. There are three fundamental factors in creating hope as a positive feeling. These three factors included goals, pathways, and agency (Snyder, \& Lopez, 2009). Snyder that studied the phenomenology of hope, believed that those people with the ability to develop and self-optimize these components are hopeful people (Snyder, Lopez, \& Pedrotti, 2010). Although numerous studies have been so far conducted to investigate neurological signs and complications of hemophilia, there are few studies on psychological problems that can cause or exacerbate cognitive diseases in hemophilic patients (Dehghan \& Memarian, 2013).

Sporadic studies have been conducted in this area around the world and demonstrated that a high percentage of hemophilia patients suffer from depression, anxiety, and moderate to severe stress (Ghavidel Heydari, 
Shirazi, \& Sanagouyemoharer, 2018; Poormansouri, Ahmadi, Shriati, \& Keikhaei, 2016). By studying the prevalence of major depressive disorder and negative behavioral patterns in children and adolescents with hemophilia, those who were randomly selected, it was found that $36 \%$ of them had at least a death wish once in the past 6 months (Ghanizadeh \& Balich-Jahromi, 2009). Therefore, psychological support and mental health protection are critical for helping children and adolescents with this chronic disease (Torres-Ortuño, Cid-Sabatel, Barbero, \& García-Dasí, 2017). Positive psychotherapy is a cognitive psychological strategy and one of the practical approaches that can be effective to obviate psychological problems of hemophilia, considering the age and characteristics of the patients (Thorn, 2017).

Research studies have shown that it is possible to train children and adolescents to learn the required skills to implicate optimism and reality-based positive thinking according to their psychological problems and to manage the mental tensions and problematic situations (Seligman \& Csikszentmihalyi, 2014; Stewart, Watson, Clark, Ebmeier, \& Deary, 2010). positive psychotherapy refers to using positive thinking interventions to deal with depression by encouraging positive emotions, raising the level of positive engagement in life, and increasing the meaning of life (Falakaflaki \& Malekitabar, 2016). These people would like to pay more attention to their merits and resources, rather than the possibility of failure and problems (Ji, Holmes, \& Blackwell, 2017; Khodabakhsh, Khosravi, \& Zarrinpour, 2015).

Studies show a direct and significant relationship between optimism and Life expectancy that increase the levels of hope (Conoley \& Conoley, 2009). Hutz, Midgett, Pacico, Bastianello and Zanon (2014) conducted research entitled "the relation of hope, optimism, self-esteem, mental well-being and personality" and found out a direct and significant relationship between optimism and hope for life, mental well-being, and self-esteem. Furthermore, Lyonotope study results indicate that positive psychological interactions can increase hope, perceived social support, and the ability to cope with social stress in individuals (Leontopoulou, 2015).

Previous studies have examined the effectiveness of optimism in Life expectancy, in other words, there are several studies conducted to shed light on the efficacy of positive psychotherapy on different groups that have psychological problems (Johnson \& Wood, 2017; Meyer, Johnson, Parks, Iwanski, \& Penn, 2012). Given the chronic nature of hemophilia, short Life expectancy index, and its most patients as children and teenagers, it is easy to imagine the myriad of the problems and significant economic burden on the healthcare system that would be created by psychological complications of this disease. The present study seeks to answer the question of if positive psychotherapy training can improve the Life expectancy of hemophilic students.

\section{Methods}

In this study, we investigated the impact of positive psychotherapy on Life expectancy in three stages of Pre-test, post-test, and follow-up in a quasi-experimental research with an experimental and a control group. The statistical population included 70 students from the Hemophilia Center of Zahedan City, Iran in 2016-2017. Of this group, 56 students who agreed to participate in this study were selected and randomly assigned to an experimental $(n=28)$ and a control group $(n=28)$.

Inclusion criteria were diagnosis of hemophilia based on medical diagnostic tests available in medical records, living in Zahedan, studying at senior elementary or junior high school, being able to cooperate and implement the program, not dealing with any other diseases except hemophilia based on a physician's opinion and medical records (some patients with asthma, kidney failure, and so on were excluded from study) and finally, not taking part in any other psychological interventions. In this study, we followed the CONSORT flow diagram illustrated in Figure 1. In this study, we follow positive psychotherapy protocol developed by Seligman and are presented in Table 1 (Seligman \& Csikszentmihalyi, 2014).

Children's Hope Scale Questionnaire: Snyder (1991) developed this questionnaire to measure the amount of hope. It has 12 items in which 8 items are used in calculating the hope index and 4 other items are deviating phrases that are not included in the rating. The range of this test score is 0 to 4 and higher scores represent a greater Life expectancy and vice versa (Snyder, 2000; Kermani, Khodapanahi, \& Mahmoud, 2011).

This project was done with the consideration of ethical issues. For each participant in the study, a meeting was held between the study administrator, the student and their parents for 30 minutes. In this session, we provided clear explanations about the research objectives, the method of research, a brief presentation of positive psychotherapy protocol and the pros and cons of the treatment. In addition, we introduced some research in these domains in which positive psychotherapy helped the individuals to manage the psychological complications of their disease more effectively. At the end of this 
Table 1. The summary of the structure and content of therapy sessions designed based on the treatment protocol proposed by Seligman

\begin{tabular}{|c|c|c|c|}
\hline Session & Topic & Content and Activities & Homework Assignment \\
\hline First & $\begin{array}{l}\text { Creating initial } \\
\text { communication }\end{array}$ & $\begin{array}{l}\text { Creating initial communication, becoming } \\
\text { familiar with the subjects, and stating the } \\
\text { objectives of holding these sessions }\end{array}$ & $\begin{array}{l}\text { Writing down all strong points } \\
\text { that the subjects can find out in } \\
\text { themselves }\end{array}$ \\
\hline Second & $\begin{array}{l}\text { Identifying personal } \\
\text { capabilities }\end{array}$ & $\begin{array}{l}\text { Discussing the method of applying the subjects' } \\
\text { strengths in their daily lives }\end{array}$ & $\begin{array}{l}\text { Writing down their strengths from } \\
\text { others' viewpoints }\end{array}$ \\
\hline Third & $\begin{array}{l}\text { Creating positive } \\
\text { emotions and mentioning } \\
\text { blessings }\end{array}$ & $\begin{array}{l}\text { Discussing the gratitude for providing } \\
\text { supplementary activities }\end{array}$ & Writing thank you letters to friends \\
\hline Fourth & $\begin{array}{l}\text { Training how to be } \\
\text { positive }\end{array}$ & $\begin{array}{l}\text { Talking about the experience of enjoying the } \\
\text { present time by focusing on the present time }\end{array}$ & $\begin{array}{l}\text { Enjoying the present and recording } \\
\text { sweet experiences the subjects had } \\
\text { in the last week }\end{array}$ \\
\hline Fifth & Positive self-talk & $\begin{array}{l}\text { Discussing constructive and active } \\
\text { responsiveness and engagement with people }\end{array}$ & $\begin{array}{l}\text { Teaching the responsiveness style } \\
\text { and improving relationships with } \\
\text { others }\end{array}$ \\
\hline Sixth & $\begin{array}{l}\text { Increasing hope and } \\
\text { setting goals }\end{array}$ & $\begin{array}{l}\text { Talking about personality traits and values which } \\
\text { the subjects wish to have in the future }\end{array}$ & $\begin{array}{l}\text { Adding abilities the subjects } \\
\text { achieved during the last week to } \\
\text { their lists }\end{array}$ \\
\hline Seventh & $\begin{array}{l}\text { Using capabilities in a } \\
\text { new way }\end{array}$ & $\begin{array}{c}\text { Talking about positive abilities and the methods } \\
\text { of developing such abilities }\end{array}$ & $\begin{array}{l}\text { Collecting positive features that } \\
\text { have been achieved so far and } \\
\text { increasing hope }\end{array}$ \\
\hline Eighth & $\begin{array}{l}\text { Summing up the } \\
\text { expression of emotions }\end{array}$ & $\begin{array}{l}\text { Talking about positive thinking and practicing the } \\
\text { acquired skills }\end{array}$ & $\begin{array}{l}\text { Increasing positive emotions, } \\
\text { determining the time of conducting } \\
\text { a post-test, and acknowledging the } \\
\text { subjects' participation }\end{array}$ \\
\hline
\end{tabular}

meeting, we asked from parents and the students to sign the consent forms.

\section{Results}

The sample consisted of 56 students with hemophilia in the age range of 10 to 25 years old. Detailed demographic characteristics of the samples and sampling flow diagram are presented in Table 2 and Figure 1, respectively.

The results of Table 3 indicate that the Life expectancy scores in the experimental group in the post-test and follow-up stage significantly increased in comparison with the control group $(\mathrm{P}<0.05)$. The post-test mean scores presented in Table 4 have moderated for covariates effect in different states of conducted tests and the result indicates that the covariate effect has been removed effectively.

Table 2. Demographic characteristics of the study samples
The results of Table 5 indicate a significant difference between the mean of post-test score $\left(\mathrm{F}_{1,25}=6.22, \mathrm{P}<0.05\right.$, $\left.\eta^{2}=0.10\right]$ and follow-up scores $\left(\mathrm{F}_{1,28}=12.04, \mathrm{P}<0.001\right.$, $\left.\eta^{2}=0.30\right)$. Obviously, the mean scores of post-test and follow-up of the experimental group were significantly higher in the Life expectancy than in the control group. Given the ETA in the post-test and follow-up phases, it can be concluded that these changes are due to the effect of the independent variable (positive psychotherapy training).

\section{Discussion}

The purpose of this study was to investigate the effectiveness of positive psychotherapy in Life expectancy of students suffered from hemophilia. The results of Table 3 indicate a significant difference between the mean scores of Life expectancy in Pre-test compared with the posttest and follow-up scores of the experimental group.

\begin{tabular}{ccccccccc}
\hline Class & \multicolumn{3}{c}{ Age, Year (\%) } & \multicolumn{2}{c}{ Sex, No. (\%) } & \multicolumn{2}{c}{ Educational Level (\%) } \\
\hline Sub-Class & $\mathbf{1 0 - 1 5}$ & $\mathbf{1 6 - 2 0}$ & $\mathbf{2 1 - 2 5}$ & Boy & Girl & Senior Elementary & $\begin{array}{c}\text { Junior High } \\
\text { School }\end{array}$ \\
\hline Control & 64.3 & 21.4 & 14.3 & $11(39.3)$ & $17(60.7)$ & 67.9 & 32.1 \\
Experimental & 67.85 & 21.43 & 10.72 & $12(42.9)$ & $16(57.1)$ & 60.7 & 39.3 \\
\hline
\end{tabular}




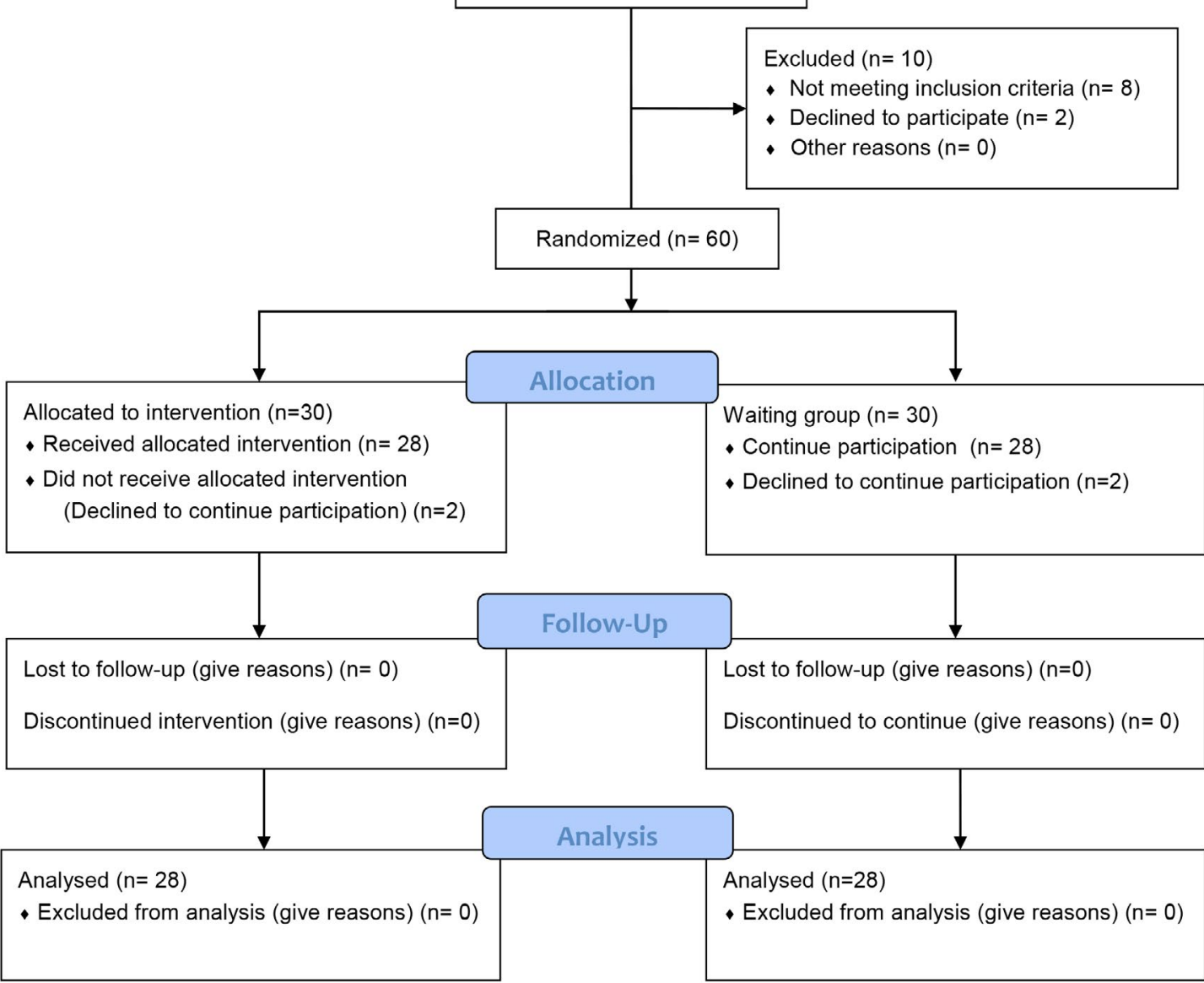

Figure 1. Sampling flow diagram

Obviously, the mean score of the Life expectancy in the post-test in the experimental group was significantly higher than that in the control group. These results are in concordance with the previous studies (Hutz et al., 2014; Leontopoulou, 2015; Sezgin \& Erdogan, 2015; Terni, 2015; Weinberg, Besser, Zeigler-Hill, \& Neria, 2016).

Researchers found a direct and significant relation between optimism and Life expectancy, well-being and self-esteem (Hutz et al., 2014). In another research, Sezgin and Erdogan (2015) showed that optimism and hope
PRACTICE in CLINICAL PSYCH LOGY

are positive and significant predictors of self-efficacy and academic achievement. Considering the results presented in Tables 3 and 4, positive psychotherapy has a stable effect. In addition, the results suggested that performing reminder sessions could consolidate and enhance the effect of positive psychotherapy.

The basic element of positive psychotherapy intervention is training participants to focus on positive emotions and resources. In other words, by increasing the positive excitements in an optimized way, the correct and posi-

Table 3. The Mean and SD of Life Expectancy at the experimental and control groups

\begin{tabular}{|c|c|c|c|c|c|}
\hline \multirow{2}{*}{ Variable } & \multirow{2}{*}{ Group } & \multirow{2}{*}{ Number } & \multicolumn{3}{|c|}{ Mean $\pm S D$} \\
\hline & & & Pre-Test & Post-Test & Follow-up \\
\hline \multirow{2}{*}{ Life Expectancy } & Experimental & 28 & $26.57 \pm 4.79$ & $35.96 \pm 4.31$ & $37.75 \pm 2.25$ \\
\hline & Control & 28 & $30.17 \pm 4.43$ & $32.75 \pm 7.34$ & $31.26 \pm 8.22$ \\
\hline
\end{tabular}


Table 4. Analysis of covariance for comparison of post-test scores in two groups

\begin{tabular}{|c|c|c|c|c|c|c|c|c|}
\hline Groups & Subscale & $\begin{array}{l}\text { Sum of } \\
\text { Squares }\end{array}$ & $\begin{array}{l}\text { Degree of } \\
\text { Freedom }\end{array}$ & $\begin{array}{l}\text { Mean } \\
\text { Squares }\end{array}$ & $\mathbf{F}$ & $\begin{array}{c}\text { Significant } \\
\text { Level }\end{array}$ & $\begin{array}{c}\text { Eta } \\
\text { Squared }\end{array}$ & $\begin{array}{l}\text { Test } \\
\text { Power }\end{array}$ \\
\hline \multirow{2}{*}{ Post-test } & Pre-test & 95.664 & 1 & 95.664 & 2.72 & 0.1 & 0.04 & 0.36 \\
\hline & Group & 218.775 & 1 & 218.775 & 6.22 & 0.01 & 0.1 & 0.68 \\
\hline \multirow{2}{*}{ Follow up } & Pre-test & 230.59 & 1 & 230.59 & 1.39 & 0.24 & 0.05 & 0.2 \\
\hline & Group & 4136.65 & 1 & 4136.65 & 12.04 & 0.001 & 0.3 & 0.99 \\
\hline
\end{tabular}

Table 5. Analysis of covariance for comparison of post-test scores in two groups

\begin{tabular}{|c|c|c|c|c|c|c|c|c|}
\hline & Sub-Scale & $\begin{array}{l}\text { Sum of } \\
\text { Squares }\end{array}$ & $\begin{array}{l}\text { Freedom of } \\
\text { Degree }\end{array}$ & $\begin{array}{l}\text { Mean } \\
\text { Squares }\end{array}$ & $\mathbf{F}$ & $\begin{array}{c}\text { Significant } \\
\text { Level }\end{array}$ & $\begin{array}{c}\text { Eta } \\
\text { Squared }\end{array}$ & Test Power \\
\hline \multirow{2}{*}{ Post-test } & Pretest & 95.664 & 1 & 95.664 & 2.72 & 0.1 & 0.04 & 0.36 \\
\hline & Group & 218.775 & 1 & 218.775 & 6.22 & 0.01 & 0.1 & 0.68 \\
\hline \multirow{2}{*}{ Follow up } & Pretest & 230.59 & 1 & 230.59 & 1.39 & 0.24 & 0.05 & 0.2 \\
\hline & Group & 4136.65 & 1 & 4136.65 & 12.04 & 0.001 & 0.3 & 0.99 \\
\hline
\end{tabular}

tive feedbacks to a difficult situation increases (Horney et al., 2011). One of the important properties of positive psychotherapy training is that the person can take its advantages without the need for a psychologist which confirms the effectiveness of this therapeutic approach in the follow-up phase (Layous, Chancellor, Lyubomirsky, Wang, \& Doraiswamy, 2011). In addition, it will increase the pleasure and comfort of the patient's life.

While additional research is absolutely necessary for this subject, the current study provides some clinical and practical implications. The results of this study highlighted the efficacy of positive psychotherapy method to increase the Life expectancy score in students suffering hemophilia. Results of our study suggest the implication of positive psychotherapy strategies to enhance life quality index and alleviate complications of hemophilia patients as an example of chronic disease. Using positive psychotherapy for students with hemophilia could improve psychological complications of hemophilia e.g. test anxiety as one of the main problems in the academic life of these patients (Ghavidel Heydari et al., 2018). We emphasize using this method by psychotherapists, caregivers, and medical staffs. Furthermore, planning to educate this method to caregivers and medical staff will improve their ability to help patients with hemophilia and psychologically manage their problems.
Regardless of how much treatment of hemophilia could be effective, patients, their families, and specialists agree that living with this disease can be difficult and frustrating. Therefore, increasing the Life expectancy has a direct and positive effect on improving the quality of life in these patients. In general, according to the study results and other similar studies, attention to new approaches of psychology and psychotherapy such as positive psychotherapy and training this method to psychology staffs can be effective in the treatment of various disorders that have psychological complications. Our results show that positive psychotherapy can be valuable in increasing Life expectancy and wellbeing in patients with chronic diseases. This study has limitation in terms of its sample size, so future studies are needed to support the obtained results.

\section{Ethical Considerations}

\section{Compliance with ethical guidelines}

All ethical principles were considered in this article. The participants were informed about the purpose of the research and its implementation stages; they were also assured about the confidentiality of their information; Moreover, They were allowed to leave the study whenever they wish, and if desired, the results of the research would be available to them. 


\section{Funding}

This research did not receive any specific grant from funding agencies in the public, commercial, or not-forprofit sectors.

\section{Authors contributions}

Carring out the experiment and writing the manuscript: Mahbobe Ghavidel Heydari, Mahmoud Shirazi, Gholam Reza Sanagouyemoharer; Planning and supervising: Mahmoud Shirazi; and Designing, implementation of the research and analyzing: Gholam Reza Sanagouyemoharer.

\section{Conflict of interest}

The authors declare no conflict of interest.

\section{Acknowledgements}

The authors would like to express Ms. Salmanian, the head of Zahedan Hemophilia Society. Our sincere thanks also go to Rahgoshaye Elm va Pajohesh Institute advisors for their helpful comments for conducting this study.

\section{References}

Cassis, F. Y., Querol, F., Forsyth, A., Iorio, A., \& Board, H. I. A. (2012). Psychosocial aspects of haemophilia: A systematic review of methodologies and findings. Haemophilia, 18(3), e101e14. [DOI:10.1111/j.1365-2516.2011.02683.x] [PMID]

Chen, C. M., Huang, K. C., Chen, C. C., Huang, S. U., Huang, C. E., Chen, Y. Y., et al. (2015). The impact of joint range of motion limitations on health-related quality of life in patients with haemophilia A: A prospective study. Haemophilia, 21(3), e176-e84. [DOI:10.1111/hae.12644] [PMID] [PMCID]

Conoley, C. W., \& Conoley, J. C. (2009). Positive psychology and family therapy: Creative techniques and practical tools for guiding change and enhancing growth. Hoboken: Wiley. [PMID] [PMCID]

Dehghan, A., \& Memarian, R. (2013). Abundance of stress, anxiety and depression in Multiple Sclerosis patients. Alborz University Medical Journal, 2(2), 82-8. [DOI:10.18869/acadpub. aums.2.2.82]

DeKoven, M., Karkare, S., Kelley, L., Cooper, D., Pham, H., Powers, J., et al. (2014). Understanding the experience of caring for children with haemophilia: Cross-sectional study of caregivers in the United States. Haemophilia, 20(4), 541-9. [DOI:10.1111/hae.12379] [PMID]
Dorgalaleh, A., Dadashizadeh, G., \& Bamedi, T. (2016). Hemophilia in Iran. Hematology, 21(5), 300-10. [DOI:10.1080/102453 32.2015.1125080] [PMID]

Falakaflaki, S., \& Malekitabar, M. (2016). Group Positive Psychotherapy Effect on Increasing the Happiness of Mothers of Children with Cochlear Implant. Practice in Clinical Psychology, 4(3), 173-82. [DOI:10.15412/J.JPCP.06040305]

Ghanizadeh, A., \& Balich Jahromi, P. (2009). Depression, anxiety and suicidal behaviour in children and adolescents with Haemophilia. Haemophilia, 15(2), 528-32. [DOI:10.1111/j.13652516.2008.01971.x] [PMID]

Ghavidel Heydari, M., Shirazi, M., \& Sanagouyemoharer, G. R. (2018). The effect of positive psychotherapy in test anxiety among Zahedan students with hemophilia. Research in Psychotherapy: Psychopathology, Process and Outcome, 21(1), 55-61.

Griggs, S. (2017). Hope and mental health in young adult college students: an integrative review. Journal of Psychosocial Nursing and Mental Health Services, 55(2), 28-35. [DOI:10.3928/02793695-20170210-04]

Horney, D. J., Smith, H. E., McGurk, M., Weinman, J., Herold, J., Altman, K., et al. (2011). Associations between quality of life, coping styles, optimism, and anxiety and depression in pretreatment patients with head and neck cancer. Head $\mathcal{E}$ Neck, 33(1), 65-71. [DOI:10.1002/hed.21407] [PMID]

Hosseini, F., Jolayi, H., Valizadeh, L., Tabaghchy Ahary, A., Hashemi, M., \& Varmazyar, Z. (2014). The knowledge of hemophilia affected adolescents on the prevention of hemophilia complications. Scientific Journal of Iranian Blood Transfusion Organization, 10(4), 372-86.

Hutz, C. S., Midgett, A., Pacico, J. C., Bastianello, M. R., \& Zanon, C. (2014). The relationship of hope, optimism, selfesteem, subjective well-being, and personality in Brazilians and Americans. Psychology, 5(6), 514-22. [DOI:10.4236/ psych.2014.56061]

Iannazzo, S., Cortesi, P. A., Crea, R., Steinitz, K., Mantovani, L. G., \& Gringeri, A. (2017). Cost-effectiveness analysis of pharmacokinetic-driven prophylaxis vs. standard prophylaxis in patients with severe haemophilia A. Blood Coagulation \& Fibrinolysis, 28(6), 425-30. [DOI:10.1097/MBC.00000000000000610] [PMID]

Jafari, S., Mohtashami, J., Alaee Karahroudi, F., Mansouri, S., \& Rassouli, M. (2016). [Perceived social support and its correlated factors in adolescents with chronic disease (Persian)] Hayat, 22(1), 65-78.

Ji, J. L., Holmes, E. A., \& Blackwell, S. E. (2017). Seeing light at the end of the tunnel: Positive prospective mental imagery and optimism in depression. Psychiatry Research, 247, 155-62. [DOI:10.1016/j.psychres.2016.11.025] [PMID]

Johnson, J., \& Wood, A. M. (2017). Integrating positive and clinical psychology: Viewing human functioning as continua from positive to negative can benefit clinical assessment, interventions and understandings of resilience. Cognitive Therapy and Research, 41(3), 335-49. [DOI:10.1007/s10608-015-9728-y]

Karimi, M., \& Haghpanah, S. (2015). The effects of economic sanctions on disease specific clinical outcomes of patients with thalassemia and hemophilia in Iran. Health Policy, 119(2), 239-43. [DOI:10.1016/j.healthpol.2014.12.011] [PMID] 
Kermani, Z., Khodapanahi, M. K., \& Mahmoud, H. (2011). [Psychometric properties of Snyder's hope scale (Persian)]. Applied Psychology, 5(3), 7-23.

Khodabakhsh, R., Khosravi, Z., \& Zarrinpour, N. (2015). [Effect of positive psychotherapy in depression symptoms and character strengths in cancer affected patients (Persian)]. Positive Psychology Research, 1(1), 35-49.

Klein, R. H., \& Nimorwicz, P. (1982). Psychosocial aspects of hemophilia in families: 1. Assessment strategies and instruments. Clinical Psychology Review, 2(2), 153-69. [DOI:10.1016/02727358(82)90009-5]

Layous, K., Chancellor, J., Lyubomirsky, S., Wang, L., \& Doraiswamy, P. M. (2011). Delivering happiness: Translating positive psychology intervention research for treating major and minor depressive disorders. The Journal of Alternative and Complementary Medicine, 17(8), 675-83. [DOI:10.1089/ acm.2011.0139] [PMID]

Leontopoulou, S. (2015). A positive psychology intervention with emerging adults. The European Journal of Counselling Psychology, 3(2), 113-36. [DOI:10.5964/ejcop.v3i2.33]

Meyer, P. S., Johnson, D. P., Parks, A., Iwanski, C., \& Penn, D. L. (2012). Positive living: A pilot study of group positive psychotherapy for people with schizophrenia. The Journal of Positive Psychology, 7(3), 239-48. [DOI:10.1080/17439760.2012.677467]

Poon, J. L., Doctor, J. N., \& Nichol, M. B. (2014). Longitudinal changes in health-related quality of life for chronic diseases: an example in hemophilia A. Journal of General Internal Medicine, 29(3), 760-6. [DOI:10.1007/s11606-014-2893-y] [PMID]

Poormansouri, S., Ahmadi, M., Shriati, A., \& Keikhaei, B. (2016). [Quality of life, depression, anxiety and stress in over-18-yearold patients with beta-Thalassaemia major (Persian)]. Scientific Journal of Iran Blood Transfus Organ, 13(1), 72-82

Rezende, S. M., Rodrigues, S. H. L., Brito, K. N. P., da Silva, D. L. Q., Santo, M. L., de Jesus Simões, B., et al. (2017). Evaluation of a web-based registry of inherited bleeding disorders: A descriptive study of the Brazilian experience with HEMOVIDAweb coagulopatias. Orphanet Journal of Rare Diseases, 12, 27. [DOI:10.1186/s13023-016-0560-6] [PMID]

Seligman, M. E., \& Csikszentmihalyi, M. (2014). Positive psychology: An introduction. In M. Csikszentmihalyi (Ed), Flow and the Foundations of Positive Psychology (pp. 279-98). Berlin: Springer. [DOI:10.1007/978-94-017-9088-8_18]

Sezgin, F., \& Erdogan, O. (2015). Academic Optimism, Hope and Zest for Work as Predictors of Teacher Self-Efficacy and Perceived Success. Educational Sciences: Theory and Practice, 15(1), 7-19. [DOI:10.12738/estp.2015.1.2338]

Shorey, H. S., Snyder, C. R., Yang, X., \& Lewin, M. R. (2003). The role of hope as a mediator in recollected parenting, adult attachment, and mental health. Journal of Social and Clinical Psychology, 22(6), 685-715.[DOI:10.1521/jscp.22.6.685.22938]

Sidonio, R., Holot, N., \& Cooper, D. L. (2017). Evaluating the psychosocial impact of hemophilia B: The bridging hemophilia $B$ experiences, results and opportunities into solutions (B-HERO-S) study. European Journal of Haematology, 98(S86), 3-4. [DOI:10.1111/ejh.12853] [PMID]

Snyder, C. R. (2000). The past and possible futures of hope. Journal of Social Clinical Psychology Review, 19(1), 11-28.
Snyder, C. R., \& Lopez, S. J. (2009). Oxford handbook of positive psychology. Oxford: Oxford University Press.

Snyder, C. R., Harris, C., Anderson, J. R., Holleran, S. A., Irving, L. M., Sigmon, S. T., et al. (1991). The will and the ways: Development and validation of an individual-differences measure of hope. Journal of Personality and Social Psychology, 60(4), 570-85. [PMID]

Snyder, C. R., Lopez, S. J., \& Pedrotti, J. T. (2010). Positive psychology: The scientific and practical explorations of human strengths. Thousand Oaks: Sage.

Sondik, E., Madans, J., \& Gentleman, J. (2010). Vital and health statistics: Summary health statistics for US adults: National health interview survey, 2009. Hyattsville, Maryland: National Center for Health Statistics. [PMID]

Stewart, M. E., Watson, R., Clark, A., Ebmeier, K. P., \& Deary, I. J. (2010). A hierarchy of happiness? Mokken scaling analysis of the Oxford happiness inventory. Personality and Individual Differences, 48(7), 845-8. [DOI:10.1016/j.paid.2010.02.011]

Terni, P. (2015). Solution-focus: Bringing positive psychology into the conversation. International Journal of Solution-Focused Practices, 3(1), 8-16. [DOI:10.14335/ijsfp.v3i1.25]

Thorn, B. E. (2017). Cognitive therapy for chronic pain: A step-bystep guide. New York: Guilford Press.

Torres-Ortuño, A., Cid-Sabatel, R., Barbero, J., \& García-Dasí, M (2017). Life experience of the adult and ageing patient with haemophilia. Practical aspects for psychological support. Vox Sanguinis, 112(4), 301-9. [DOI:10.1111/vox.12501] [PMID]

Weinberg, M., Besser, A., Zeigler-Hill, V., \& Neria, Y. (2016). Bidirectional associations between hope, optimism and social support, and trauma-related symptoms among survivors of terrorism and their spouses. Journal of Research in Personality, 62, 29-38. [DOI:10.1016/j.jp. 2016.03.002] 